\title{
Student Engagement and the Learning Incentive Program: Evidence and Applications
}

\author{
Joel R. Anderson (joel.anderson@acu.edu.au) \\ School of Psychology, Faculty of Health Sciences \\ Australian Catholic University, Australia
}

\begin{abstract}
This paper presents the Learning Incentive Program (LIP), which is an innovative teaching resource designed to enhance a range of learning-relevant outcomes through increasing student engagement while maintaining intrinsic motivation. Specifically, the LIP involves interactive weekly online formative quizzes, primarily designed to encourage engagement. As incentive for regularly engaging in course content, completion of weekly tasks allows access to course materials for that topic (e.g., lecture notes can be obtained prior to the lecture as an incentive for engaging with the LIP). The LIP is theoretically informed, and this paper presents data supporting its effectiveness. Designed to encourage regular interaction with course materials, the LIP encourages online student-driven engagement with the material, provides interactive feedback by explaining incorrect answers, and assists students to track their progress across the semester. Evidence and applications are discussed.
\end{abstract}

Keywords: Student engagement; intrinsic motivation; online program; self-determination theory; cognitive evaluation theory

Topical buzzwords of the education lexicon have been filling popular and scientific discourse with a renewed energy in recent years, and a growing body of pragmatic evidence in their favour now exists. For example, empirical findings pertaining to student motivation and particularly intrinsic motivation (i.e., motivation stemming from an inherent interest or enjoyment; Deci \& Ryan, 1985; Ryan \& Deci, 2000a) continue to evolve, contributing to understanding how motivation can best be harnessed to facilitate learning and positive learning outcomes. More recently, research has revealed the increased importance of student engagement, which is a construct that refers to the student's level of active involvement in a given learning activity (Christenson \& Anderson, 2002; Fredricks, Blumenfeld, \& Paris, 2004; Kahu, 2013). ${ }^{1}$ Together these two constructs might play a vital role in enhanced learning and approaches to teaching; recent evidence has revealed that engagement fully

\footnotetext{
${ }^{1}$ Engagement as a term itself has been around for over 80 years (e.g., Pace \& McFee, 1960; Tyler, 1930). However, the recent re-appropriation of the term to include quality of effort and active involvement in the construct (Junco, 2012; Kuh \& Gonyea, 2015) has rejuvenated the term.
}

mediates the well-established relationship between motivation and achievement (Reeve \& Tseng, 2011). In statistical terms, this means that when the role of engagement in achievement is considered, the direct effect of the student's motivation in achievement drops to zero. This suggests that engagement is an important construct that should be considered in combination with motivational processes in terms of helping students to reach their academic goals.

The primary purpose of this paper is to present the Learning Incentive Program (LIP); a teaching initiative that was designed to bolster levels of student engagement whilst maintaining motivation. ${ }^{2}$ The LIP is an online program designed to help university students to engage with their course content, and has built-in stimuli designed to incentivise regular engagement. The LIP was conceived in a fashion that is theoretically and empirically informed, and then empirically tested. This paper first discusses motivational learning theories before presenting the LIP. After presenting the protocol, I present evidence of its effectiveness before closing with a discussion on its potential application and directions for future research.

Self-determination theory (SDT; Deci \& Ryan, 2002; Deci \& Ryan, 2011) is a macro-theory of motivation $^{3}$, that has recently been applied to the study of factors involved in student motivation (Niemiec \& Ryan, 2009; Reeve, 2002; Reeve, Deci, \& Ryan, 2004). The theory has a focus on types of motivational phenomena, rather than quantities, which influences a range of studentrelevant outcomes including performance and wellbeing. The basic premise of the theory is that all students have inherent relevant growth tendencies, including innate curiosity, intrinsic motivation, and psychological needs (Deci \& Ryan, 2008; Reeve et al., 2004). SDT emphasises that high-quality levels of student engagement can be

\footnotetext{
${ }^{2}$ This teaching initiative was designed by the author in 2013, and the data presented within this paper was collected in 2014.

${ }^{3}$ There are five interrelated mini-theories that comprise SDT - cognitive evaluation theory is the reviewed within this paper as the theory that informed the LIP. The others (i.e., basic needs theory, organismic integration theory, goal contents theory, and causality orientations theory) are not directly relevant to this paper, and so are not reviewed.
} 
facilitated by bolstering inner motivational resources (Reeve \& Halusic, 2009), rather than the traditional focus of other learning theories on expectations, goals, and beliefs. Finally, SDT affords suggestions for how educators can nurture and cultivate these motivational resources (Niemiec \& Ryan, 2009).

The theory acknowledges that this basic premise (i.e., that students have a natural tendency towards intrinsically motivated learning) is not evident in all students, and then tries to resolve this paradox by identifying which factors are motivation-nurturing and which are motivationthwarting (Reeve et al., 2004; Ryan \& Deci, 2000b). Once these factors are identified, subsequent steps can be taken to ameliorate or attenuate their effects, respectively. Because the majority of research in this domain has focused on secondary education, in which educators spent relatively continuous amounts of time with students in a regular learning environment, this research has focused on the interaction between student motivations and classroom conditions. Because this same luxury of environment and contact regularity is not afforded to tertiary education, the question of what role educators can play in fostering SDTinformed motivational phenomena with tertiary students remains unanswered.

The LIP is based on an incentive system. ${ }^{4}$ Although there is a solid tradition of research supporting notions that extrinsic rewards can be used to alter behaviour (Skinner, 1953), other literature (e.g., Deci, 1971; Deci, Koestner, \& Ryan, 2001) has shown that under certain conditions, extrinsic rewards can reduce intrinsic motivation (i.e., levels of spontaneous satisfaction during a learning activity that can initiate and maintain engagement levels). ${ }^{5}$ More specifically, previous literature shows that external events can dichotomise the effects, sometimes enhancing the effects of intrinsic motivations (e.g., Danner \& Lonky, 1981; Zuckerman, Porac, Lathin, \& Deci, 1978) but other times diminishing these same effects (e.g., Amabile, DeJong, \& Lepper, 1976; Lepper \& Greene, 1975; for meta-analyses, see Cerasoli, Nicklin, \& Ford, 2014; Deci, Koestner, \& Ryan, 1999). Thus, in designing the LIP, I turned to the sub-theories comprising SDT to answer questions of how to engage and motivate tertiary students without damaging intrinsic motivation levels. In particular, cognitive evaluation theory

\footnotetext{
${ }^{4}$ I would like to highlight the distinction that the LIP is an incentive system (that encourages voluntary commitment to the mastery or accomplishment of the knowledge offered) rather than a reward system (that rewards non-autonomous behaviours, and is known to diminish intrinsic motivation).

${ }^{5}$ Cognitive evaluation theory represents the contributions of social psychology to self-determination theory.
}

(CET; Deci \& Ryan, 1980; see also Ryan, 1982) attempts to explain how feedback and rewards (i.e., external events), might affect intrinsically motivated processes. This knowledge is particularly necessary given that the major aim of the LIP is to incentivise engagement without affording extrinsic motivation (and thus decreasing intrinsic motivations).

A central component of CET is that events influencing perceptions of competence or autonomy will (necessarily) affect intrinsic motivation levels (Reeve, 2012; Ryan \& Deci, 2000b). Specifically, increased feelings of competence and feelings of autonomy should play a vital role in sustaining and increasing intrinsic motivation. The theory also posits two functional aspects to all external events or rewards. These are a controlling aspect in which compliant behaviour is met with a reward, and the informational aspect in which rewards are used to communicate competence or improvement. The theory argues that the relative salience of the controlling aspect compared to the informational aspect will determine the effect of the external event on the level of intrinsic motivation. Thus, events that are heavy in controlling aspects diminish intrinsic motivation levels through reducing autonomy, while those that are high in informational aspects foster intrinsic motivation levels through enhanced perceptions of competence (for a review on reward contingencies, see Deci et al., 1999). When designing the LIP, careful consideration was taken to make it an incentive system, rather than a reward system. Thus, an effective incentive should encourage engagement, and feelings of competence and autonomy, while ensuring that there are plentiful informational aspects and limited controlling aspects.

A final piece of relative theoretical knowledge pertains to the multi-dimensional elaborations of the motivational orientations. For example, many researchers originally adhered to a single-construct theory of intrinsic motivation, but contemporary researchers have further compartmentalized this into more nuanced and useable forms (e.g., Deci, 1975; Vallerand et al., 1992). Current knowledge suggests that intrinsic motivation can be driven by the need to know (i.e., curiosity, epistemic need for understanding), to accomplish (i.e., creation and mastery), or to experience stimulation (i.e., sensory and aesthetic motivation). Similarly, extrinsic motivation has also been further classified into three sub-classifications, comprising external regulation (i.e., the imposition of material rewards or constraints), introjection (i.e., the internalisation of a formerly external regulation), and identification (i.e., the student has chosen to value and judge their education as important). Each of these taxonomies has been independently studied, and relate to motivation broadly, and educational 
motivation specifically, in qualitatively different ways. (Deci \& Ryan, 1985, 1991). ${ }^{6}$

The LIP was grounded in theory (as discussed above), but also built from existing empirical findings. For example, the idea of engaging with the material prior to the class has proven to be effective at increasing learning gains (e.g., Dindia, 2013; Moravec, Williams, Aguilar-Roca, \& O'Dowd, 2010), and regular quizzes on unit content have been shown to improve overall grades in undergraduate students (Hattikudur \& Postle, 2011). More specifically, there is evidence that regular quizzes promotes course material retention more effectively than if a comparable amount of time was spent on conventional retention techniques (McDaniel, Agarwal, Huelser, McDermott, \& Roediger, 2011), specifically this effect holds for quizzes that are formative (i.e., aim to determine student progress through learning goals) rather than summative (i.e., aim to assess level of mastery of content at the completion of learning). More importantly, evidence exists that quizzes facilitate the successful transfer of learnt knowledge into bolstered performance on exams (McDaniel, Thomas, Agarwal, McDermott, \& Roediger, 2013). More broadly, research has shown that encouraging students to familiarise themselves with content for the upcoming lecture increases engagement, grades, and satisfaction (Carlson \& Winquist, 2011). Finally, quizzes that are delivered online have the option of providing immediate feedback; correct feedback increases self-efficacy while feedback on incorrect answers can aid learning through detailed explanations of the correct answer (Kotecha, 2012, 2013).

The design of the LIP centres on a formative quiz that uses incentives as the external event for behavioural modification. Thus, during the design of the LIP, careful consideration was given to the conditions under which rewards are allocated and how the recipient perceives them. Specifically, the LIP aims to increase engagement levels of tertiary students with course materials, by providing an incentive to do so (i.e., rewarding engagement), rather than indiscriminately rewarding for nonautonomous learning. This is easily achieved; however, the LIP specifically is designed to provide an incentive for students using the informational aspect of the reward whilst simultaneously bolstering feelings of competence and feelings of autonomy. The LIP is discussed in detail below.

\footnotetext{
${ }^{6}$ I note that there are indeed different approaches to learning that can meaningfully affect learning (e.g., deep learning, strategic learning, surface learning, etc.). In the interest of saving space, this literature has not been reviewed in this paper, however informative reviews are available (see Pask, 1976; Schmeck, 2013).
}

\section{The Learning Incentive Program}

The LIP is a learning initiative focusing on the facilitation of student engagement with course content at regular intervals throughout the semester. Offering a participation-based incentive encourages this regular engagement. It aims to increase engagement while sustaining motivation, and increase the quality of the student outcomes, including confidence and preparedness, plus enjoyment of learning. It consists of a program of optional weekly online activities that are designed to re-engage the students with the previous week's content as well as prepare them for upcoming content. Specifically, activities usually take the form of an easy short multiple-choice quizapproximately two thirds based on content from the assigned reading for the upcoming week, and the remaining questions based on content from the previous week. Items are marked only to give the students feedback: students are marked as answering correctly or incorrectly, and incorrect answers are then explained (i.e., what the selected answer actually refers to, plus what the correct option was). These marks are not counted towards the assessment or final grade of the participating student. Students can access these quizzes at any time, allowing them to also use the LIP for revision purposes.

A key aspect of the LIP involves the incentive for participation. This comprises incentivising students who participate with an accuracy of at least $75 \%{ }^{7}$ Each week, students who reached this minimum accuracy were given access to the lecture notes for the upcoming lecture. This incentive was designed to facilitate an intrinsic motivation to accomplish; key researchers in the field have argued that to create a sense of novel accomplishment and competence, individuals will interact with their environment (Deci, 1975; Deci \& Ryan, 1985, 1991). The LIP offers a chance to interact with the educational environment is a way that is not typically available in tertiary education systems, thus offering the chance to increase intrinsic motivation. Students were allowed multiple attempts at the quiz, however this was rarely needed due to the simplicity of the task (i.e., the quiz was a formative assessment that was designed to evidence engagement with course materials, and not designed to be an index of how effective their learning has been). Students largely prefer having access to lecture notes, but the reported tangible outcomes of this are limited. It increases the reported levels of enjoyment of the subject (Susskind, 2004) but does not enhance academic performance (Rankin \& Hoaas, 2001), making it an ideal incentive for engagement

\footnotetext{
${ }^{7}$ Students who participated in the LIP in 6 or more of the 10 weeks for which it was offered had an average accuracy of $89 \%$.
} 
(without disadvantaging students who don't participate). Those students who did not complete the task prior to the lecture were granted access to the lecture notes after the weekly lecture was delivered. In summary, the LIP has the following key functions:

- Engagement prior to the lecture: Rather than encountering material for the first time during the lecture, students will already be familiar with terminology and concepts.

- Engagement is regular: Systematic learning and regular feedback allows students to adjust the focus of their study time accordingly.

- Interactive: Quiz feedback usually only involves 'correct' or 'incorrect.' In the LIP, answering an online quiz question correctly increases self-efficacy while wrong answers can aid learning through detailed explanations of the correct answer.

- Course-relevant incentives: Participating students are offered access to course lecture notes upon completion of the weekly quiz. Thus, students wishing to have the lecture notes during the lecture need to engage with the material.

- Revision: The online nature of the LIP allows weekly quizzes to be revisited, including reassessing items that were previously answered incorrectly.

At this point, I would like to acknowledge that the incentive in the LIP could be seen as encouraging extrinsic motivation, specifically external regulation, because of the reward attached. However, as argued above, I propose that the incentive component encourages the intrinsic motivation to accomplish. I make this claim based on the knowledge that attempting to master difficult techniques in order to experience personal satisfaction is indeed an example of intrinsic motivation, and that the LIP is an example of this in the education domain.

\section{Results}

In this section I present data from a class of students who had the option of using the LIP as a learning resource whilst undertaking a Research Design and Statistics course during the second year of an undergraduate psychology degree. The sample comprised 73 Australian students (age range: 19 - 48: $M=23.10, S D=5.73$, 61 females). All students enrolled in the unit were asked to (voluntarily) contribute feedback at three time points throughout the semester. More specifically, all students enrolled in this unit were given class time to fill out a five minute survey at weeks 1,5 , and 10 out of a 12 -week semester. ${ }^{8}$ The faculty at

\footnotetext{
${ }^{8}$ These weeks were chosen to allow a spread of feedback across the semester but to also miss critical periods of the semester, such as assessment and
}

the hosting university approved the process of evaluation, ${ }^{9}$ and students were offered access to the aggregated results assessing the effectiveness of the program at the end of the semester.

\section{Correlates with grades}

There was a moderate to strong positive correlation between the frequency of use of the LIP and the end of semester grade (i.e., a final score out of 100 for the unit), $r(71)=.61, p<.001$. More specifically, as the frequency of weeks in the semester during which the student engaged with the LIP increased, so did their final grade). This effect becomes even more pronounced when you only include students who were using the LIP, $r(35)=$ $.70, p<.001$.

This correlational data allows no claims to causality; given that participating in the LIP was optional, it is equally as plausible that students who were already likely to be high achievers/be highly motivated to do well in this unit are more likely to participate. One way to further explore this finding is to track self-reported learning-relevant outcomes across the semester and compare these ratings between students who used the LIP and those who did not.

\section{Individual use of the LIP}

The efficacy of the LIP at the individual-level was quantified by collecting student self-report ratings on perceptions of their own levels of engagement, confidence, preparedness, and enjoyment of the subject. All students were asked to respond to a series of items on a 10-point scale ranging from 1 (not at all) to 10 (completely). Each participant responded to five dimensions, each with a single item, which are presented in Table 1, below. Students were also asked how frequently they were engaging with the LIP (the computer based nature of the task allowed verification of this), and were also classified as users ( $n=34$; based on at least one use over the 10 weeks course) or non-users ( $n=39$; based on not engaging with the LIP at all over the course of the semester).

examination periods, which have the potential to affect the content of the evaluation. Data was collected in the period from March to May, 2014.

${ }^{9}$ The data collected relating to the feedback and evaluation of the LIP was approved by the Human Research Ethics Committee (HREC: 2014 20V) of the Australian Catholic University, which is institution that the students supplying the data were enrolled at. 
Table 1

Items used to evaluate the effectiveness of the Learning Incentive Program

\begin{tabular}{ll}
\hline Dimension & Item \\
\hline Engagement & $\begin{array}{l}\text { How engaged do you feel with the } \\
\text { content and teaching of this unit? }\end{array}$ \\
Confidence & $\begin{array}{l}\text { How confident do you feel about your } \\
\text { abilities this unit? }\end{array}$ \\
Preparedness & $\begin{array}{l}\text { How prepared do you feel for this unit? } \\
\text { Enjoyment }\end{array}$ \\
\hline
\end{tabular}

To explore self-reported perceptions, a series of mixed-design ANOVAs were run on the data supplied by the students. The factors were LIP (2: users, non-users) and time (3: time 1 , time 2, time 3) with repeated measures on the latter factor. Mean and standard error statistics are presented in Figure 1, below. As can be seen, there is a definite
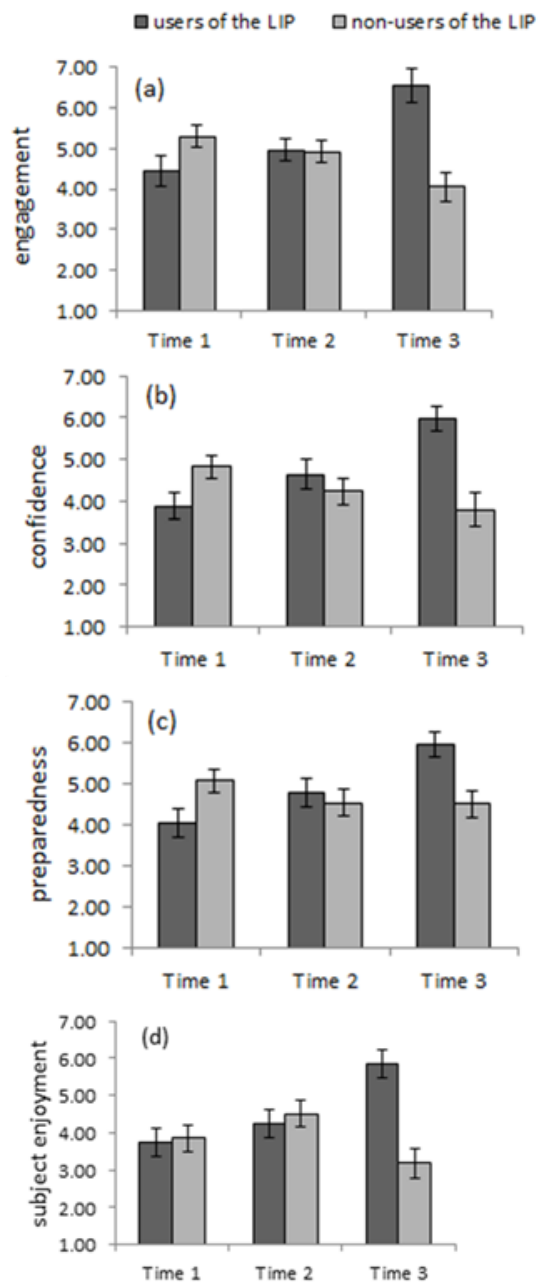

Figure 1. Mean (and standard error) self-report scores on learning relevant outcomes of (a) engagement, (b) confidence, (c) preparedness, and (d) subject enjoyment. trend that users of the LIP reported increases on all outcomes, while non-users reported decreases on all outcomes across time.

Indeed, analyses revealed a similar pattern of results for all competencies; LIP users had significantly higher ratings on the level of subject enjoyment than non-users. However, for all 5 competencies there was a significant interaction between these variables. Statistics are presented in Table 2, below. Post-hoc analyses will decompose the effects for each variable below.

Engagement. Across the course of the semester, levels of engagement significantly increased for LIP users, and decreased for non-users. LIP users reported significantly higher levels of engagement at time 3 than at both time 1 and time $2(\mathrm{p}<.001)$. Ratings between times 1 and 2 did not differ ( $\mathrm{p}=$ .441). Conversely, non-users reported significantly lower levels of engagement at time 3 than at both time 1 and time $2(\mathrm{p}<.003)$. Ratings between times 1 and 2 did not differ $(p=1.00)$. Finally, there were differences between LIP users and nonusers at time 3; users reported significantly higher levels of engagement than non-users $(p<.001)$. This effect did not exist at the earlier time points ( $\mathrm{p}>$ .073).

Confidence. Across the course of the semester, levels of confidence significantly increased for LIP users, and decreased for non-users. LIP users reported significantly higher levels of confidence at time 3 than at both time 1 and time $2(\mathrm{p}<.001)$, and confidence was higher at time 2 than time 1 (p $=.038$ ). Conversely, non-users reported significantly lower levels of confidence at time 3 than at time $1(\mathrm{p}=.001)$. Ratings between times 1 and 2, and 2 and 3, did not differ $(\mathrm{p}>.060)$.

Finally, there were differences between LIP users and non-users at times 1 and 3; non-users reported significantly higher levels of confidence than users at time $1(\mathrm{p}=.029)$, and this trend was reversed by the end of the semester to the extent that users reported significantly higher levels of confidence than non-users at time $3(\mathrm{p}<.001)$. There were no differences at time $2(\mathrm{p}=.374)$.

Preparedness. Across the course of the semester, levels of preparedness significantly increased for LIP users $\left(\mathrm{p}<.001, \eta_{\mathrm{p}}{ }^{2}=.442\right)$. LIP users reported significantly higher levels of preparedness at time 3 than at both time 1 and time $2(\mathrm{p}<.001)$. Ratings between times 1 and 2 did not differ $(p=.139)$. There was no effect for non-users $(p=.125)$. Finally, there were differences between LIP users and non-users at times 1 and 3; non-users reported significantly higher levels of preparedness than users at time $1(\mathrm{p}=.024)$, and this trend was reversed by the end of the semester to the extent that users reported significantly higher levels of preparedness than non-users at time $3(\mathrm{p}=.002)$. There were no differences at time $2(p=.625)$. 
Table 2

Statistical statements of significance, testing differences between users and non-users of the Learning Incentive Program on learning-relevant outcomes across the course of a semester.

\begin{tabular}{|c|c|c|c|}
\hline Dimension & $\begin{array}{c}\text { Time } \\
\text { (main effect) }\end{array}$ & $\begin{array}{c}\text { LIP } \\
\text { (main effect) } \\
\end{array}$ & Interaction between Time and LIP \\
\hline Engagement & $p=.335$ & $p=.105$ & $F(2,104)=22.07, p<.001, \eta_{p}^{2}=.298$ \\
\hline Confidence & $p=.306$ & $p=.123$ & $F(1.75,99.68)=23.12, p<.001, \eta_{p}^{2}=.292$ \\
\hline Preparedness & $p=.078$ & $p=.369$ & $F(2,104)=12.84, p<.001, \eta_{p}{ }^{2}=.198$ \\
\hline Enjoyment & $p=.016$ & $p=.038$ & $F(2,104)=14.79, p<.001, \eta_{p}^{2}=.206$ \\
\hline
\end{tabular}

Notes: Confidence ratings were corrected for issues with sphericity using a Greenhouse-Geisser adjustment. Full statistical statements are not presented for main effects, as these are superseded by interaction effects.

Subject enjoyment. Across the course of the semester, levels of enjoyment significantly increased for LIP users $\left(p<.001, \eta_{p}{ }^{2}=.517\right)$. LIP users reported significantly higher levels of subject enjoyment at time 3 than at both time 1 and time 2 $(\mathrm{p}<.001)$. Ratings between times 1 and 2 did not differ $(p=.386)$. There was no effect for non-users $(p=.065)$. Finally, there were differences between LIP users and non-users at time 3; users reported significantly higher levels of subject enjoyment ( $\mathrm{p}$ $<.001)$. There were no significant differences at time 1 or $2(\mathrm{p}<.598)$.

\section{Predicting grades from LIP related-outcomes}

The LIP is related to increases of self-reported engagement, confidence, preparedness, and subject enjoyment. Given this finding, if these outcomes are predictors of grades, and the LIP leads to increases in these outcomes, then this would also add to the evidence for the utility of the LIP. As such, the proportion of variance in grades was estimated by regressing these outcomes against the final unit grades. A forced entry regression revealed that these four variables accounted for a significant $71.00 \%$ of the variance in final grades, $F(4,58)=35.89, p<.001$, which can be considered a large effect (Cohen's $\left.f^{2}=2.25\right)^{10}$. Engagement and confidence were both strong positive predictors of student grades. Regression coefficients and squared semi-partial correlations for each predictor are presented in Table 3.
Evidence 4: Cohort effects - failing grades. The final piece of evidence to support the effectiveness of the LIP is to compare the grades of the cohort of students who had the option of the using the LIP with the grades of the students completing the same unit the previous year (i.e., before the LIP was available). The teaching staff, content, and assessment were constant across cohorts. Across all assessments, the cohort of students who had the option of the using the LIP had higher grades than the cohort of students who did not have this same option. The scores are presented in Figure 2.

A chi-square test of independence was performed to examine the relationship between the cohorts (before and after the LIP was introduced) and final grade awarded (pass or fail). The relation between these variables was significant, $\chi^{2}(2)=$ 9.044, $\mathrm{p}=.002$ (see Table 4, below). The cohort of students who had the option to use the LIP were more likely to be awarded a passing grade than the cohort of students who did not have the option.

In summary, here is presented evidence that for this cohort of students, using the LIP was related to decreased amounts of failing grades awarded across the unit (i.e., final scores $<50 \%$ ) and increases in final grade scores (i.e., percentage scores). It was also related to increases in levels of student engagement, confidence, levels of preparedness, and subject enjoyment. Finally, LIP-based increases in student engagement and

Table 3

Unstandardised $(B)$ and standardised $(\beta)$ regression coefficients, and semi-partial correlations in a model predicting student grades from self-report levels of engagement, confidence, preparedness, and subject enjoyment.

\begin{tabular}{lllll}
\cline { 2 - 5 } & & & & \\
& & & & \multicolumn{1}{c}{$s r^{2}$} \\
Engagement & $\mathbf{2 . 8 8 4}$ & $\mathbf{0 . 6 2 8}$ & $\mathbf{0 . 5 5 1}$ & $\mathbf{3 2 3}^{*}$ \\
Confidence & $\mathbf{1 . 9 4 9}$ & $\mathbf{0 . 7 4 0}$ & $\mathbf{0 . 3 2 7}$ & $\mathbf{. 8 6}^{* *}$ \\
Preparedness & 0.313 & 0.767 & 0.050 & .029 \\
Enjoyment & -0.189 & 0.591 & -0.035 & .022 \\
\hline
\end{tabular}

Note: ${ }^{*} p<.05,{ }^{* *} p<.001$, significant coefficients presented in boldface. Constant $=37.03(S E=2.59)$.

\footnotetext{
${ }^{10}$ Effect size for this regression was based on observed $R^{2}$ and calculated using software by Soper (2015) based on the work of Cohen (1988).
} 


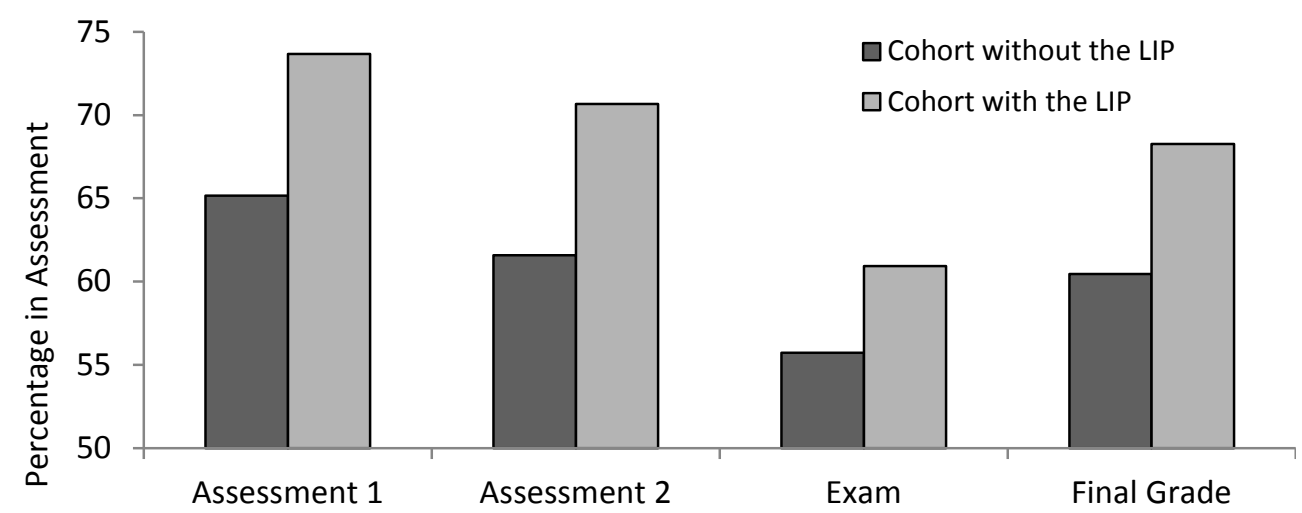

Figure 2. Average grades (final grade, and as a function of assessment) for the cohort of students the year before and the year after the Learning Incentive Program (LIP) was introduced.

Table 4

Contingency table with observed (and expected) cell totals comparing frequencies of pass and fail grades between 2 cohorts of students taking the same unit.

\begin{tabular}{|c|c|c|c|}
\hline & $\begin{array}{c}\text { Cohort } \\
\text { without } \\
\text { LIP }\end{array}$ & $\begin{array}{l}\text { Cohort with } \\
\text { LIP }\end{array}$ & $\begin{array}{c}\text { Marginal } \\
\text { Rows } \\
\text { Totals } \\
\end{array}$ \\
\hline $\begin{array}{l}\text { Passing } \\
\text { grade }\end{array}$ & $\begin{array}{l}71(77.85) \\
{[0.60]}\end{array}$ & $\begin{array}{l}113(106.15) \\
{[0.44]}\end{array}$ & 184 \\
\hline $\begin{array}{l}\text { Failing } \\
\text { grade }\end{array}$ & $\begin{array}{l}17(10.15) \\
{[4.62]}\end{array}$ & $\begin{array}{l}7(17.85) \\
{[3.39]}\end{array}$ & 24 \\
\hline $\begin{array}{l}\text { Marginal } \\
\text { Column } \\
\text { Totals }\end{array}$ & 88 & 120 & 208 \\
\hline
\end{tabular}

confidence then further predict higher end of subject grades.

\section{Discussion}

\section{Application of the LIP}

Having demonstrated evidence for the effectiveness of this theory-based learning resource, the potential applications of the LIP can be discussed. Given that the LIP was designed for use in the tertiary education sector, which is based on the premise of self-guided learning, the need to offer students learning resources that bolster engagement is paramount. Therefore, the online nature of the LIP makes it an ideal candidate for a wide range of student circumstances, including full-time or part-time workloads, and distancebased or on-campus modes of learning. It is suitable for use by a range of student capabilities, it allows high-achievers to excel whilst also allowing those struggling with content to identify and understand areas that need improvement. Finally, it is suitable to a wide range of topics. The data presented in this paper was from a class on Research Design and Statistics, however, it could equally as well be used in any subject. The applied use of the LIP is limited only to the imagination of the educator choosing to implement it.

The LIP can clearly be beneficial to students. It allows them to track the amount of work they are doing outside of class hours, and which components of the course they are excelling in or which areas of the course need attention. It also acts as a tool for revision. However, a topic that has not yet been discussed is how the LIP might be beneficial to educators. It can allow the educator to see where the class (at the individual level, or at the cohort level) is excelling or struggling, which can inform the educator how to best allocate revision time and to refine course content for following years.

There are several areas in which the LIP could be developed. First, the LIP could be made into a smart phone or web-based application. This would allow the LIP to be extended to include engagement during the lecture. For example, students could take quizzes throughout the lecture to ostensibly check that the content is being understood, with the real aim of sustaining engagement. Second, technology used to record lectures could be used to turn small portions of the lecture into clips (similar to a video podcast), which could then be linked to feedback system in the LIP. In this way, students frequently answering incorrectly about a topic could be given access to a 'replay' of the related portion of the lecture to clarify any misunderstanding.

Finally, the incentive element of the LIP could be eliminated, or restructured. Indeed, the incentive aspect of the program is secondary to the fact that it facilitates engagement, and as such the incentive might not be necessary at all.

\section{Limitations of the LIP}

The LIP, as presented in this paper, is not without its limitations. One primary concern that needs acknowledgement is the self-selecting nature of the program. Indeed, it is highly likely that students who chose to participate in the LIP were 
already higher in levels of engagement, confidence, and preparedness, and had a higher natural enjoyment of learning than those students who chose not to participate. An experimentally designed follow-up study, in which students are randomly allocated into a group of LIP users, or LIP non-users, would settle this issue. However, the ethics commission at the hosting university would not allow either: (a) some students to be denied access to learning materials in this manner, due to fairness concerns, or (b) that students were required to engage with the LIP (i.e., compulsory use was not allowed). Thus, I acknowledge that the data presented here is limited by the self-selection bias; however, given the findings comparing the cohort with access to the LIP to the cohort from the year before who did not have the same access, this confound is of limited concern for the interpretation of the findings of the paper.

\section{Summary and Concluding Remarks}

Tertiary institutions cannot change student levels of intrinsic motivation, and this is particularly the case with certain topics or subjects. Indeed, many students approach their tertiary education purely as a means to an end, and take no enjoyment from learning in its own right. With this in mind, the established relationship between intrinsically motivated learning and achievement might not ever become realised for some students. Some research has revealed that engagement levels fully mediate this relationship (Reeve \& Tseng, 2011), which suggests that educators should focus on increasing engagement where possible, obviously without thwarting the beneficial effects of intrinsic motivation. In this paper, I presented the Learning Incentive Program, which is a theoretically driven and empirically informed learning tool that educators can use to increase the chances that their students attain their educational goals by encouraging higher levels of engagement. The argument for student engagement is simple and parsimonious; increases in time spent studying a topic increases knowledge, and feedback combined with practice facilitates deeper understanding (Kuh, 2003, 2009). Although the focus of the program is on the engagement, the LIP has several secondary features, including incentivising increased time spent studying, incentivising regular engagement with course materials, and allowing the provision of feedback that is infrequent in tertiary education.

The LIP was developed in an attempt to increase learning outcomes for students through facilitating their levels of engagement with course content by incentivising intrinsic motivation to accomplish via engagement in online quizzes. It also aims to increase the quality of their learning gains and grades, plus increase their overall enjoyment of learning. The LIP promotes engagement with course material at regular intervals throughout the semester, and incentivising involvement in the program with participationbased incentives and course-relevant rewards. Specifically, the LIP offers weekly and interactive online quizzes that offer course-relevant incentives in exchange for engaging with course material prior to the lecture. In summary, the LIP incentivises students for increasing their levels of engagement. The LIP was shown to increase positive learning outcomes, and is an innovative and simple addition to the range of learning resources available to tertiary educators.

\section{Declarations and Acknowledgments}

The learning incentive program was awarded a FHS (Faculty of Health Sciences) teaching citation at the Australian Catholic University in 2014 for outstanding contributions to student learning. The author declares no potential conflicts of interest with respect to the research, authorship, and/or publication of this article. This research was unfunded.

\section{Author Biography}

Joel Anderson is a social psychologist with research interests in automatic social processes and intergroup relationships. He currently holds a lectureship position in the School of Psychology at Australian Catholic University in Melbourne, Australia.

\section{References}

Amabile, T. M., DeJong, W., \& Lepper, M. R. (1976). Effects of externally imposed deadlines on subsequent intrinsic motivation. Journal of Personality and Social Psychology, 34, 92-98. doi:10.1037/0022-3514.34.1.92

Carlson, K. A., \& Winquist, J. R. (2011). Evaluating an active learning approach to teaching introductory statistics: A classroom workbook approach. Journal of Statistics Education, 19, 1-23. Retrieved from http://eric.ed.gov/?id=EJ921447

Cerasoli, C. P., Nicklin, J. M., \& Ford, M. T. (2014). Intrinsic motivation and extrinsic incentives jointly predict performance: A 40year meta-analysis. Psychological bulletin, 140(4), 980-1008. doi:10.1037/a0035661

Christenson, S. L., \& Anderson, A. R. (2002). Commentary: The centrality of the learning context for student's academic enabler skills. School Psychology Review, 31, 378-393.

Cohen, J. (1988). Statistical power analysis for the behavioral sciences Hillsdale, NJ: Laurence Erlbaum.

Danner, F. W., \& Lonky, E. (1981). A cognitivedevelopmental approach to the effects of rewards on intrinsic motivation. Child 
Development, 52, 1043-1052. doi:10.2307/1129110

Deci, E. L. (1971). Effects of externally mediated rewards on intrinsic motivation. Journal of Personality and Social Psychology, 18, 105115. doi:10.1037/h0030644

Deci, E. L. (1975). Intrinsic motivation. New York, NY: Plenum Press.

Deci, E. L., Koestner, R., \& Ryan, R. M. (1999). A meta-analytic review of experiments examining the effects of extrinsic rewards on intrinsic motivation. Psychological bulletin, 125, 627668. doi:10.1037/0033-2909.125.6.627

Deci, E. L., Koestner, R., \& Ryan, R. M. (2001). Extrinsic rewards and intrinsic motivation in education: Reconsidered once again. Review of educational research, 71(1), 1-27. doi:10.3102/00346543071001001

Deci, E. L., \& Ryan, R. (2002). Overview of selfdetermination theory: An organismic dialectical perspective. In E. L. Deci \& R. Ryan (Eds.), Handbook of self-determination research (pp. 3-33).

Deci, E. L., \& Ryan, R. M. (1980). The empirical exploration of intrinsic motivational processes. Advances in experimental social psychology, 13(2), 39-80.

Deci, E. L., \& Ryan, R. M. (1985). Intrinsic motivation and self-determination in human behavior: Springer Science \& Business Media.

Deci, E. L., \& Ryan, R. M. (1991). A Motivational Approach to Self: Integration in Personality. In R. Dienstbier (Ed.), Perspectives on motivation (Vol. 38, pp. 237-288). Lincoln, NE: University of Nebraska Press.

Deci, E. L., \& Ryan, R. M. (2008). Selfdetermination theory: A macrotheory of human motivation, development, and health. Canadian Psychology/Psychologie canadienne, 49, 182185. doi:10.1037/a0012801

Deci, E. L., \& Ryan, R. M. (2011). Selfdetermination theory. In P. Van Lange, A. Kruglanski, \& E. Higgins (Eds.), Handbook of theories of social psychology (pp. 416-433).

Dindia, L. (2013). Pre-lecture activities in undergraduate science courses. Teaching Innovation Projects, 3, 1-6. Retrieved from http://ir.lib.uwo.ca/tips/vol3/iss1/6

Fredricks, J. A., Blumenfeld, P. C., \& Paris, A. H. (2004). School engagement: Potential of the concept, state of the evidence. Review of Educational Research, 74, 59-109. doi:10.3102/00346543074001059

Hattikudur, S., \& Postle, B. R. (2011). Effects of Test-Enhanced Learning in a Cognitive Psychology Course. Journal of Behavioral and Neuroscience Research, 9, 151-157.

Junco, R. (2012). The relationship between frequency of Facebook use, participation in Facebook activities, and student engagement.
Computers \& Education, 58, 162-171. doi:10.1016/j.compedu.2011.08.004

Kahu, E. R. (2013). Framing student engagement in higher education. Studies in Higher Education, 38(5), 758-773. doi:10.1080/03075079.2011.598505

Kotecha, M. (2012). Teaching mathematics and statistics: promoting students' engagement and interaction. Retrieved from http://eprints.lse.ac.uk/42008/1/Teaching_math ematics_and_statistics\%28lsero\%29.pdf

Kotecha, M. (2013). Addressing mathematics and statistics anxiety. Mathematics Today, 49(6), 259.

Kuh, G. D. (2003). What we're learning about student engagement from NSSE: Benchmarks for effective educational practices. Change: The Magazine of Higher Learning, 35(2), 24-32. doi:10.1080/00091380309604090

Kuh, G. D. (2009). The national survey of student engagement: Conceptual and empirical foundations. New Directions for Institutional Research, 2009(141), 5-20. doi:10.1002/ir.283

Kuh, G. D., \& Gonyea, R. M. (2015). The role of the academic library in promoting student engagement in learning. College \& Research Libraries, 76, 359-385. doi:10.5860/crl.76.3.359

Lepper, M. R., \& Greene, D. (1975). Turning play into work: Effects of adult surveillance and extrinsic rewards on children's intrinsic motivation. Journal of Personality and Social Psychology, 31, 479-486. doi:10.1037/h0076484

McDaniel, M. A., Agarwal, P. K., Huelser, B. J., McDermott, K. B., \& Roediger, H. L. (2011). Test-enhanced learning in a middle school science classroom: The effects of quiz frequency and placement. Journal of Educational Psychology, 103, 399-414. doi:10.1037/a0021782

McDaniel, M. A., Thomas, R. C., Agarwal, P. K., McDermott, K. B., \& Roediger, H. L. (2013). Quizzing in middle-school science: successful transfer performance on classroom exams. Applied Cognitive Psychology, 27, 360-372. doi:10.1002/acp.2914

Moravec, M., Williams, A., Aguilar-Roca, N., \& O'Dowd, D. K. (2010). Learn before lecture: a strategy that improves learning outcomes in a large introductory biology class. CBE-Life Sciences Education, 9(4), 473-481. doi:10.1187/cbe.10-04-0063

Niemiec, C. P., \& Ryan, R. M. (2009). Autonomy, competence, and relatedness in the classroom: Applying self-determination theory to educational practice. Theory and Research in Education, 7, 133-144. doi:10.1177/1477878509104318 
Pace, C. R., \& McFee, A. (1960). The college environment. Review of educational research, 311-320. Retrieved from http://www.jstor.org/stable/1168853

Pask, G. (1976). Styles and strategies of learning. British journal of educational psychology, 46(2), 128-148.

Rankin, E. L., \& Hoaas, D. J. (2001). The use of power point and student performance. Atlantic economic journal, 29, 113.

Reeve, J. (2002). Self-determination theory applied to educational settings. In E. L. Deci \& R. Ryan (Eds.), Handbook of self-determination research (pp. 183-203). Rochester, NY: University of Rochester Press.

Reeve, J. (2012). A self-determination theory perspective on student engagement Handbook of research on student engagement (pp. 149172): Springer.

Reeve, J., Deci, E. L., \& Ryan, R. M. (2004). Selfdetermination theory: A dialectical framework for understanding sociocultural influences on student motivation. In D. McInerney \& S. Van Etten (Eds.), Big Theories Revisited (Vol. 4, pp. 31-60).

Reeve, J., \& Halusic, M. (2009). How K-12 teachers can put self-determination theory principles into practice. Theory and Research in Education, 7, 145-154. doi:10.1177/1477878509104319

Reeve, J., \& Tseng, C.-M. (2011). Agency as a fourth aspect of students' engagement during learning activities. Contemporary Educational Psychology, 36, 257-267. doi:10.1016/j.cedpsych.2011.05.002

Ryan, R. M. (1982). Control and information in the intrapersonal sphere: An extension of cognitive evaluation theory Journal of Personality and Social Psychology (Vol. 43, pp. 450-461).

Ryan, R. M., \& Deci, E. L. (2000a). Intrinsic and extrinsic motivations: Classic definitions and new directions. Contemporary Educational Psychology, 25, 54-67. doi:10.1006/ceps.1999.1020

Ryan, R. M., \& Deci, E. L. (2000b). Selfdetermination theory and the facilitation of intrinsic motivation, social development, and well-being. American Psychologist, 55(1), 68.

Schmeck, R. R. (2013). Learning strategies and learning styles. Carbondale, IL: Springer Science \& Business Media.

Skinner, B. F. (1953). Science and human behavior. New York, NY: Simon and Schuster.

Soper, D. S. (2015). Effect Size Calculator for Multiple Regression [software]. Retrieved from http://www.danielsoper.com/statcalc

Susskind, L. (2004). Negotiation training: are you getting your money's worth? Boston, MA: Harvard Business School Publishing Corporation.
Tyler, R. (1930). A course in history of education. Educational Research Bulletin, 9, 133-135. Retrieved from http://www.jstor.org/stable/1471315

Vallerand, R. J., Pelletier, L. G., Blais, M. R., Briere, N. M., Senecal, C., \& Vallieres, E. F. (1992). The academic motivation scale: A measure of intrinsic, extrinsic, and amotivation in education. Educational and psychological measurement, 52(4), 1003-1017. doi:10.1177/0013164492052004025

Zuckerman, M., Porac, J., Lathin, D., \& Deci, E. L. (1978). On the importance of self-determination for intrinsically-motivated behavior. Personality and Social Psychology Bulletin, 4, 443-446. doi:10.1177/014616727800400317 